JAMA | Original Investigation

\title{
Effect of Oral Methylprednisolone on Clinical Outcomes in Patients With IgA Nephropathy The TESTING Randomized Clinical Trial
}

Jicheng Lv, MD; Hong Zhang, PhD; Muh Geot Wong, PhD; Meg J. Jardine, PhD; Michelle Hladunewich, MD; Vivek Jha, MD; Helen Monaghan, PhD; Minghui Zhao, MD; Sean Barbour, MD; Heather Reich, MD; Daniel Cattran, MD; Richard Glassock, MD; Adeera Levin, FRCPC; David Wheeler, FRCP; Mark Woodward, PhD; Laurent Billot, MSc; Tak Mao Chan, MD; Zhi-Hong Liu, MD; David W. Johnson, MD; Alan Cass, FRACP; John Feehally, MD; Jürgen Floege, MD; Giuseppe Remuzzi, MD; Yangfeng Wu, MD; Rajiv Agarwal, MD; Hai-Yan Wang, MD; Vlado Perkovic, PhD; for the TESTING Study Group

IMPORTANCE Guidelines recommend corticosteroids in patients with IgA nephropathy and persistent proteinuria, but the effects remain uncertain.

OBJECTIVE To evaluate the efficacy and safety of corticosteroids in patients with IgA nephropathy at risk of progression.

DESIGN, SETTING, AND PARTICIPANTS The Therapeutic Evaluation of Steroids in IgA Nephropathy Global (TESTING) study was a multicenter, double-blind, randomized clinical trial designed to recruit 750 participants with IgA nephropathy (proteinuria greater than $1 \mathrm{~g} / \mathrm{d}$ and estimated glomerular filtration rate [eGFR] of 20 to $120 \mathrm{~mL} / \mathrm{min} / 1.73 \mathrm{~m}^{2}$ after at least 3 months of blood pressure control with renin-angiotensin system blockade] and to provide follow-up until 335 primary outcomes occurred.

INTERVENTIONS Patients were randomized $1: 1$ to oral methylprednisolone $\left(0.6-0.8 \mathrm{mg} / \mathrm{kg} / \mathrm{d}_{\text {; }}\right.$ maximum, $48 \mathrm{mg} / \mathrm{d})(\mathrm{n}=136)$ or matching placebo $(n=126)$ for 2 months, with subsequent weaning over 4 to 6 months.

MAIN OUTCOMES AND MEASURES The primary composite outcome was end-stage kidney disease, death due to kidney failure, or a $40 \%$ decrease in eGFR. Predefined safety outcomes were serious infection, new diabetes, gastrointestinal hemorrhage, fracture/osteonecrosis, and cardiovascular events. The mean required follow-up was estimated to be 5 years.

RESULTS After randomization of 262 participants (mean age, 38.6 [SD, 11.1] years; 96 [37\%] women; eGFR, $59.4 \mathrm{~mL} / \mathrm{min} / 1.73 \mathrm{~m}^{2}$; urine protein excretion, $2.40 \mathrm{~g} / \mathrm{d}$ ) and 2.1 years' median follow-up, recruitment was discontinued because of excess serious adverse events. Serious events occurred in 20 participants (14.7\%) in the methylprednisolone group vs 4 (3.2\%) in the placebo group ( $P=.001$; risk difference, $11.5 \%$ [95\% Cl, 4.8\%-18.2\%]), mostly due to excess serious infections (11 [8.1\%] vs 0; risk difference, $8.1 \%$ [95\% Cl, 3.5\%-13.9\%]; $P<.001)$, including 2 deaths. The primary renal outcome occurred in 8 participants $(5.9 \%)$ in the methylprednisolone group vs 20 (15.9\%) in the placebo group (hazard ratio, 0.37 [95\% $\mathrm{Cl}, 0.17-0.85]$; risk difference, $10.0 \%$ [95\% $\mathrm{Cl}, 2.5 \%-17.9 \%] ; P=.02)$.

CONCLUSIONS AND RELEVANCE Among patients with IgA nephropathy and proteinuria of $1 \mathrm{~g} / \mathrm{d}$ or greater, oral methylprednisolone was associated with an increased risk of serious adverse events, primarily infections. Although the results were consistent with potential renal benefit, definitive conclusions about treatment benefit cannot be made, owing to early termination of the trial.

TRIAL REGISTRATION clinicaltrials.gov Identifier: NCT01560052

Supplemental content

CME Quiz at

jamanetwork.com/learning
Author Affiliations: Author affiliations are listed at the end of this article.

Group Information: The TESTING Study Group members are listed at the end of this article.

Corresponding Authors: Hong Zhang, PhD, Renal Division, Department of Medicine, Peking University First Hospital, Beijing 100034, China (hongzh@bjmu.edu.cn); Vlado Perkovic, PhD, The George Institute for Global Health, UNSW Sydney, One King St, PO Box M201, Newtown, NSW 2042, Australia (vperkovic@georgeinstitute.org.au). 
mmunoglobulin A nephropathy is the most prevalent primary glomerular disease, particularly in the Asia-Pacific region. ${ }^{1}$ Up to $30 \%$ of all people with IgA nephropathy will eventually develop end-stage kidney disease (ESKD) ${ }^{2}$; decreased kidney function, persistent proteinuria, and hypertension are the strongest risk factors. ${ }^{3,4}$

The use of renin-angiotensin system (RAS) blockade has been shown to reduce the risk of kidney failure in patients with highrisk IgA nephropathy ${ }^{5,6}$ and is thus guideline-recommended therapy. ${ }^{7,8}$ Despite this, a large proportion of individuals will still develop ESKD, so better treatments are required.

Although IgA nephropathy is an immune-complexmediated glomerulonephritis, the role of immunosuppression remains controversial. ${ }^{8}$ A meta-analysis of previous trials suggested substantial benefit with corticosteroid therapy, but trial quality was suboptimal, most trials were single-center, and adverse outcomes were poorly reported. ${ }^{9}$ Additionally, the efficacy of corticosteroids in patients with impaired kidney function was not evaluated, and limited data exist for people of Eastern or South-Asian origin. ${ }^{10-12}$ Global guidelines currently suggest a 6-month course of corticosteroids for individuals with urinary protein excretion persistently above $1 \mathrm{~g} / \mathrm{d}$ and an estimated glomerular filtration rate (eGFR) greater than $50 \mathrm{~mL} / \mathrm{min} / 1.73 \mathrm{~m}^{2}$ after at least 3 months of appropriate supportive care. However, it is acknowledged that this weak recommendation is based on low-quality evidence. ${ }^{7}$

In addition, a recent trial of immunosuppression in IgA nephropathy ${ }^{13}$ found that the addition of immunosuppression to intensive supportive care in 162 European participants reduced proteinuria but did not reduce the rate of eGFR decline over 3 years. As a result, it remains uncertain whether corticosteroid therapy is beneficial in IgA nephropathy and how any benefits might trade off against potential risks.

The present study was designed to test the efficacy and safety of full-dose corticosteroid therapy in preventing clinically important kidney outcomes in patients with high-risk IgA nephropathy.

\section{Methods}

\section{Study Design and Patients}

The Therapeutic Evaluation of Steroids in IgA Nephropathy Global (TESTING) study was an investigator-initiated, multicenter, double-blind, randomized clinical trial comparing oral methylprednisolone with placebo on the risk of important kidney outcomes in people with IgA nephropathy receiving appropriate supportive therapy, including blood pressure control and RAS blockade.

The study was overseen by a management committee, coordinated by an academic research organization (The George Institute for Global Health), and designed to be conducted in up to 100 centers from China, Australia, India, Canada, and Malaysia. Ethical approval to conduct the trial was obtained from Peking University, the University of Sydney, and the ethics committees of each study center; all participants provided written informed consent. The study protocol is available in Supplement 1.

\section{Key Points}

Question Do corticosteroids safely prevent loss of kidney function in patients with IgA nephropathy receiving optimal supportive therapy?

Findings This randomized clinical trial that included 262 participants was stopped early (after 28 of the 335 planned events) due to a significantly increased risk of serious adverse events with oral methylprednisolone vs placebo $(14.7 \%$ vs $3.2 \%$, primarily excess infections); at that point, the primary efficacy outcome favored methylprednisolone (5.9\% vs 15.9\%).

Meaning Oral corticosteroid therapy was associated with an increased risk of serious adverse events; the effect on kidney outcomes remains uncertain due to the limited number of events.

Eligibility required a diagnosis of primary IgA nephropathy proven on kidney biopsy, an eGFR between 20 and $120 \mathrm{~mL} / \mathrm{min} / 1.73 \mathrm{~m}^{2}$ (calculated using the Chronic Kidney Disease Epidemiology Collaboration creatinine equation ${ }^{14}$ ), and urinary protein excretion greater than $1 \mathrm{~g} / \mathrm{d}$. Exclusion criteria included a strong indication, or contraindication, for corticosteroid therapy, based on the judgement of the treating physician (patients were included if the patient and physician had clinical equipoise regarding the use of the treatment), or the use of systemic immunosuppressive therapy in the previous year.

The full inclusion and exclusion criteria are detailed in the eTable 1 in Supplement 2. Given the planned multinational recruitment and potential for differences in response by ethnicity, self-reported racial origin by patients was collected and recorded by the investigators, based on prespecified categories.

\section{Randomization and Masking}

Patients who were adherent to treatment and who had persistent proteinuria greater than $1 \mathrm{~g} / \mathrm{d}$ during the run-in period were randomly assigned 1:1 via a password-protected encrypted website interface to receive oral methylprednisolone or matching placebo, stratified by region; proteinuria $(<3 \mathrm{~g} / \mathrm{d}$ or $\geq 3 \mathrm{~g} / \mathrm{d})$; eGFR ( $<50 \mathrm{~mL} / \mathrm{min} / 1.73 \mathrm{~m}^{2}$ or $\left.\geq 50 \mathrm{~mL} / \mathrm{min} / 1.73 \mathrm{~m}^{2}\right)$; and kidney biopsy findings (endocapillary proliferation status [E1 or E0] according to the Oxford classification). ${ }^{15}$ Randomization was performed using a minimization algorithm based on the stratification variables; the algorithm was centrally generated and used by all centers to minimize any imbalances in key variables. Patients, investigators, site staff, and sponsors were masked to treatment assignment for the duration of the study.

\section{Procedures}

Potentially eligible participants entered a run-in period from 4 to 12 weeks, during which treatment was adjusted to ensure that they were receiving the maximum labeled or tolerated dose of RAS blockade, along with optimized blood pressure control according to Kidney Disease: Improving Global Outcomes (KDIGO) guidelines for glomerulonephritis and hypertension, for at least 3 months prior to randomization. Study 
treatment consisted of 0.6 to $0.8 \mathrm{mg} / \mathrm{kg} / \mathrm{d}$ of oral methylprednisolone or matching placebo (rounded to the nearest $4 \mathrm{mg}$ and with a maximal dose of $48 \mathrm{mg} / \mathrm{d}$ ) for 2 months, then tapered by $8 \mathrm{mg} / \mathrm{d}$ each month, with a total treatment period of 6 to 8 months.

Participants were followed up at regular intervals, for a planned mean of at least 5 years. Study visits occurred monthly for 3 months after randomization, then every 3 months until month 12 , and every 12 months until the end of the study. Additional telephone or face-to-face (at the choice of the investigator) visits were required at 3-month intervals to ascertain kidney end points or adverse events.

Laboratory evaluation of all specimens was performed in a national central laboratory in China and at local laboratories in other countries. Serum creatinine levels were measured using enzymatic or Jaffe methods with calibration traceable to isotope dilution mass spectrometry.

\section{End Points}

The primary composite end point was initially defined as the first occurrence of a 50\% decrease in eGFR, the development of ESKD (defined as a need for maintenance dialysis or kidney transplantation and adjudicated by a blinded, independent committee), or death due to kidney disease. Based on consensus recommendations from a workshop sponsored by the National Kidney Foundation and the US Food and Drug Administration on renal end points, ${ }^{16,17}$ the steering committee decided to modify the creatinine-based component of the primary end point to a $40 \%$ decrease in eGFR in November 2014, prior to knowledge of any results, while other components of the primary end point remained unchanged.

Secondary end points included the composite of ESKD, $40 \%$ decrease in eGFR, and all-cause death; the composite of ESKD, 50\% decrease in eGFR, and all-cause death; and each of ESKD, death due to kidney disease, and all-cause death. The secondary end points also included proteinuria reduction evaluated by time-averaged proteinuria and eGFR slope across all postrandomization study visits. Prespecified exploratory end points included (1) a $25 \%$ decrease in eGFR assessed separately or as part of a composite with ESKD and all-cause death; (2) annual slope in the inverse of serum creatinine level; (3) proteinuria remission at months 6,12 , and 24; and (4) disappearance of hematuria at last follow-up. A statistical analysis plan (Supplement 3) was developed by a subgroup of the steering committee, blinded to any information about study outcomes.

\section{Adverse Events and Safety}

Predefined safety outcomes were all-cause mortality, total serious adverse events, serious infections, new diabetes, gastrointestinal hemorrhage, fracture or osteonecrosis, and cardiovascular events. Serious adverse events (SAEs) were defined according to the International Conference on Harmonization Guideline for Clinical Safety Data Management.

Interim Analyses and Data Monitoring

An independent data and safety monitoring committee (DSMC) met twice yearly to review efficacy and safety data; 2 formal interim efficacy analyses were planned when one-third and two-thirds of the primary end points had occurred, using stopping boundaries defined using the O'Brien Fleming method, while the decisions about stopping for harm were not based on predefined statistical rules. The DSMC could recommend terminating the study early if there was clear and substantial evidence of benefit or if the risk of adverse events was determined to likely substantially outweigh the potential benefits (Supplement 4).

\section{Statistical Analysis}

The initial sample-size calculations assumed an annual combined event rate for the primary end point (50\% eGFR decrease, ESKD, and death due to kidney disease) of 7\%, requiring 1300 participants to detect a 30\% relative risk reduction in the primary end point with $90 \%$ power $(a=.05)$. A $30 \%$ risk reduction was selected because it was the upper bound of the $95 \%$ confidence interval in a meta-analysis of previous trials assessing steroids for IgA nephropathy. ${ }^{9}$ After the primary end point was modified to include a $40 \%$ reduction in eGFR, the estimated annual event rate increased to $12 \%$ based on data from a large Chinese cohort ${ }^{18}$ and a previous trial, ${ }^{10}$ and the required sample size was reduced to 750 participants to provide more than $90 \%$ power to detect a $30 \%$ risk reduction with methylprednisolone. The trial was event-driven throughout, with a total of 335 primary outcomes expected over a mean follow-up of 5 years.

All analyses were conducted according to the intentionto-treat principle. The effect of treatment on the primary composite end point was estimated using an unadjusted Cox proportional hazards model. The proportionality assumption was assessed by plotting $\log \{-\log [\mathrm{S}(\mathrm{t})]\}$ and assessing whether the curves were parallel and with a test of interaction between time and treatment in the Cox model. Data for patients were censored at the date of death or the date of data extraction for those still alive. Because of small numbers, other composite end points as well as the individual components were summarized as the proportions of patients with at least 1 event and compared using Fisher exact test. Confidence intervals for risk differences were calculated using the Newcombe score method.

The yearly rate of eGFR decline was calculated as the mean of the individual slopes obtained from individual linear regressions of eGFR over time. Time-averaged proteinuria was calculated as the weighted mean of all postrandomization measurements, with weights representing the time elapsed since the previous measurement. Mean eGFR slopes and mean timeaveraged proteinuria values were compared across treatments using $t$ tests. Overall differences in eGFR and proteinuria over time were estimated using linear mixed models including all postrandomization measurements. Fixed effects included baseline measurement, month (as a categorical variable with 5 categories), treatment group, and the interaction between month and treatment group. A random intercept by participant was used to model within-participant correlations. Complete remission of proteinuria was defined as achievement of urinary protein level less than $200 \mathrm{mg} / \mathrm{d}$, and partial remission as 50\% or greater proteinuria reductions, with achieved urine protein 
less than $1 \mathrm{~g} / \mathrm{d}$. Details on the analysis of exploratory end points are included in the statistical analysis plan (Supplement 3).

All $P$ values were 2 -sided, and $P$ values less than .05 were considered to indicate statistical significance. Formal adjustment for multiple comparisons was not performed, but analyses were interpreted conservatively in light of the number of outcomes assessed, and effects on secondary outcomes should be considered exploratory.

The homogeneity of the treatment effects on the primary outcome across specified subgroups was tested by adding interaction terms to the Cox models, with predefined subgroups including proteinuria ( $<3.0 \mathrm{vs} \geq 3.0 \mathrm{~g} / \mathrm{d}$ ), eGFR ( $<50 \mathrm{vs}$ $\geq 50 \mathrm{~mL} / \mathrm{min} / 1.73 \mathrm{~m}^{2}$ ), endocapillary hypercellularity on histological scoring (yes or no), and baseline maximum tolerated dose of RAS blockade (>80\%, 50\%-80\%, and $<50 \%$ achieved of maximum labeled dose). All analyses were performed using SAS version 9.4 (SAS Institute).

\section{Results}

Between May 2012 and November 2015, 523 potentially eligible patients were screened, of whom 262 (48.8\%) were eligible and underwent randomization (136 to methylprednisolone, 126 to placebo) (Figure 1). Recruitment was stopped early, and study treatment discontinued among randomized participants, owing to an excess of SAEs (mostly infections) in the corticosteroid group, based on advice from the DSMC at a regularly scheduled meeting in November 2015 that concluded that the trial should not continue in its current form; the full recommendations of the DSMC are reported in Supplement 5. The steering committee accepted this advice and decided to terminate the study intervention on this basis on November 13, 2015.

After termination of study intervention, patients still receiving study drug were unblinded and those receiving methylprednisolone were asked to return for a safety-assessment visit; all participants were asked to return for an additional study visit at which updated informed consent for ongoing data collection, and additional information regarding study outcomes, was obtained. After termination, the study began transitioning from the treatment phase to continuing follow-up while participants were no longer receiving randomized therapy; a transitional analysis was conducted and is reported here.

Participants were recruited from China and Australia. Centers in India, Canada, and Malaysia joined the study later because of funding timing and were preparing to enroll participants when recruitment was stopped, but no patients had been recruited to the trial from these countries.

The 2 randomized groups had similar characteristics at baseline (Table 1; eTable 2 in Supplement 2). Overall, mean age was 38.6 (SD, 11.1) years, 96 women (37\%) were enrolled, mean eGFR overall was $59.4(25.0) \mathrm{mL} / \mathrm{min} / 1.73 \mathrm{~m}^{2}$, and 24-hour urine protein excretion was 2.40 (1.94) g/d. Blood pressure levels at entry were well controlled and similar in the 2 groups during follow-up (eFigure 1 in Supplement 2). The median time between biopsy and randomization was 139 days (interquartile range [IQR], 107-244 days).

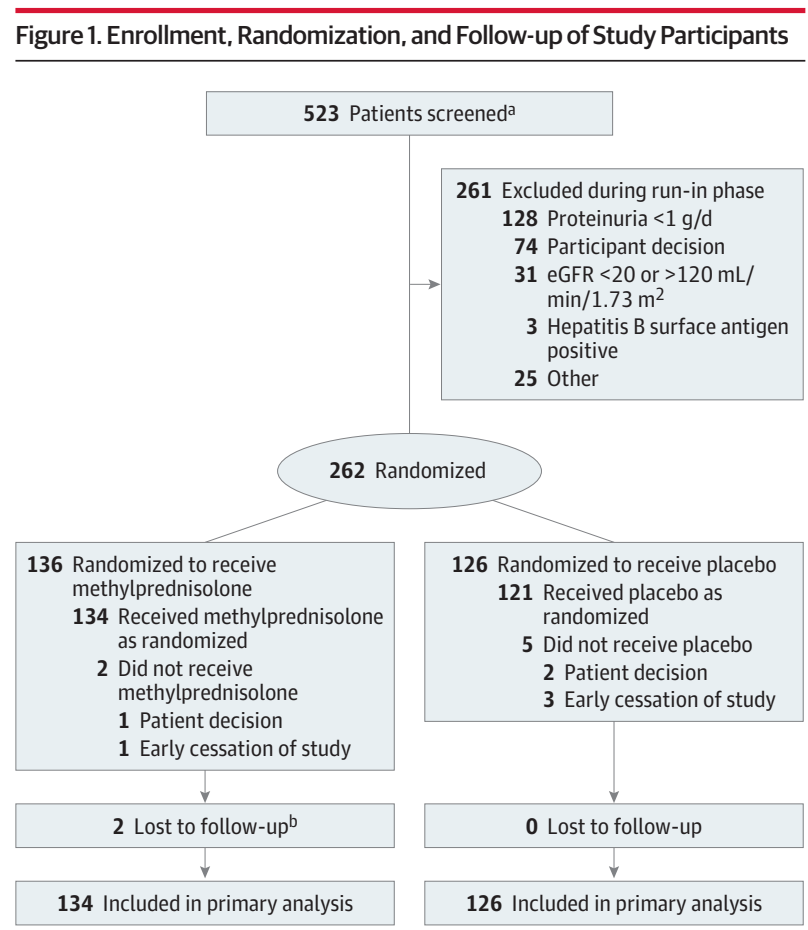

eGFR indicates estimated glomerular filtration rate.

a Patients were prescreened by the local investigator for eligibility, and 523 patients signed consent and entered the run-in phase; prescreening data were not collected.

b One participant moved overseas and could not be contacted; a second could not be contacted despite many attempts.

At the time of this transitional analysis, participants had been in the study for a median of 25 months (range, 5.7-45.3 months). A total of 226 (86\%) had completed study treatment and were in the follow-up phase at the time the steering committee made the decision to discontinue recruitment and study therapy.

Twenty-eight SAEs were reported in 20 participants (14.7\%) in the methylprednisolone group compared with 4 SAEs in 4 (3.2\%) in the placebo group (relative risk, 4.63 [95\% CI, 1.63 to 13.2]; $P=.001$ by Fisher exact test) (Table 2 and Figure 2), equating to a risk difference of $11.5 \%$ (95\% CI, $4.8 \%$ to $18.2 \%$ ). Most adverse events occurred in the first 3 months of treatment. This was mainly driven by an excess of serious infections (2 fatal) among 11 patients (8.1\%) in the methylprednisolone group, compared with no serious infections in the placebo group (risk difference, 8.1\% [95\% CI, $3.5 \%$ to $13.9 \%$ ]; $P<.001$ ). One patient in the placebo group died of stroke after commencing dialysis. Effects on SAE rates were broadly consistent according to predefined baseline subgroups (eFigure 2A in Supplement 2), but small event numbers limited subgroup power.

The primary composite renal outcome occurred in 8 participants (5.9\%) in the methylprednisolone group and 20 (15.9\%) in the placebo group (hazard ratio, 0.37 [95\% CI, 0.17 to 0.85 ]; $P=.02$; risk difference, $10.0 \%$ [95\% CI, $2.5 \%$ to $17.9 \%$ ]) (Figure 3), including 4 (2.9\%) and 10 (7.9\%) participants, 


\begin{tabular}{|c|c|c|}
\hline \multirow[b]{2}{*}{ Characteristics } & \multicolumn{2}{|l|}{ №. (\%) } \\
\hline & $\begin{array}{l}\text { Methylprednisolone } \\
(n=136)\end{array}$ & $\begin{array}{l}\text { Placebo } \\
(n=126)\end{array}$ \\
\hline Age, mean (SD), $\mathrm{y}^{\mathrm{a}}$ & $38.6(11.5)$ & $38.6(10.7)$ \\
\hline Women & $50(36.8)$ & $46(36.5)$ \\
\hline \multicolumn{3}{|l|}{ Race } \\
\hline Chinese & $130(95.6)$ & $121(96.0)$ \\
\hline White & $5(3.7)$ & $3(2.4)$ \\
\hline Southeast Asian & $1(0.7)$ & $2(1.6)$ \\
\hline Smoker & $34(25.0)$ & $31(24.6)$ \\
\hline Body mass index ${ }^{b}$ & $24.4(4.5)$ & $23.4(3.7)$ \\
\hline Hypertension & $71(52.2)$ & $52(41.3)$ \\
\hline \multicolumn{3}{|l|}{ Blood pressure, mean (SD), $\mathrm{mm} \mathrm{Hg}$} \\
\hline Systolic & $123.9(14.7)$ & $124.3(11.6)$ \\
\hline Diastolic & $79.3(10.5)$ & $79.8(9.9)$ \\
\hline Urine protein excretion, mean (SD), g/d & $2.55(2.45)$ & $2.23(1.11)$ \\
\hline Urine red blood cells per HPF, median (range) & $9.5(2.0-32.0)$ & $8.3(3.0-26.0)$ \\
\hline Microscopic hematuria & $74(62.2)$ & $64(62.1)$ \\
\hline Serum creatinine, mean (SD), mg/dl & $1.5(0.6)$ & $1.6(0.6)$ \\
\hline Estimated GFR, mean (SD), $\mathrm{ml} / \mathrm{min} / 1.73 \mathrm{~m}^{2 \mathrm{c}}$ & $60.0(24.8)$ & $58.6(25.2)$ \\
\hline \multicolumn{3}{|l|}{ Estimated GFR category } \\
\hline$\geq 50 \mathrm{~mL} / \mathrm{min} / 1.73 \mathrm{~m}^{2}$ & $83(61.5)$ & $70(56.9)$ \\
\hline $30-49 \mathrm{~mL} / \mathrm{min} / 1.73 \mathrm{~m}^{2}$ & $41(30.4)$ & $38(30.9)$ \\
\hline$<30 \mathrm{~mL} / \mathrm{min} / 1.73 \mathrm{~m}^{2}$ & $11(8.2)$ & $15(12.2)$ \\
\hline Total cholesterol, mean (SD), mg/dl & $188.9(39.0)$ & $191.8(51.1)$ \\
\hline \multicolumn{3}{|l|}{ Oxford histological score ${ }^{d}$} \\
\hline M1 & $76(57.6)$ & $75(61.0)$ \\
\hline E1 & $43(31.6)$ & $30(23.8)$ \\
\hline S1 & $94(71.2)$ & $89(72.4)$ \\
\hline TO & $51(38.6)$ & $43(35.0)$ \\
\hline $\mathrm{T} 1$ & $58(43.9)$ & $60(48.8)$ \\
\hline $\mathrm{T} 2$ & $23(17.4)$ & $20(16.3)$ \\
\hline $\mathrm{CO}$ & $54(41.5)$ & $57(45.6)$ \\
\hline $\mathrm{C} 1$ & $59(45.4)$ & $49(39.2)$ \\
\hline $\mathrm{C} 2$ & $17(13.1)$ & $19(15.2)$ \\
\hline Previous systematic corticosteroid therapy & $5(3.7)$ & $3(2.4)$ \\
\hline Previous other immunosuppressant therapy & $8(5.9)$ & $6(4.8)$ \\
\hline ACE inhibitors & $83(61.0)$ & $76(60.3)$ \\
\hline ARBs & $56(41.2)$ & 49 (38.9) \\
\hline \multicolumn{3}{|c|}{ Dose of ACE inhibitor or ARB (\% of maximum labeled dose) ${ }^{\mathrm{e}}$} \\
\hline$>80$ & $66(48.5)$ & $57(45.2)$ \\
\hline $50-80$ & $58(42.6)$ & $52(41.3)$ \\
\hline$<50$ & $10(7.4)$ & $14(11.1)$ \\
\hline Dose not specified & $2(1.5)$ & $3(2.4)$ \\
\hline
\end{tabular}

Abbreviations: ACE, angiotensin-converting enzyme; ARB, angiotensin II receptor blocker; GFR, glomerular filtration rate: HPF, high-power field; RAS, renin-angiotensin system.

${ }^{\text {a N}}$ No patients younger than 18 years were enrolled.

${ }^{\text {b } C a l c u l a t e d ~ a s ~ w e i g h t ~ i n ~ k i l o g r a m s ~}$ divided by height in meters squared.

c Estimated with the use of the Chronic Kidney Disease Epidemiology Collaboration creatinine equation.

${ }^{\mathrm{d}} \mathrm{M} 1$ indicates mesangial score $>0.5$; E1, endocapillary hypercellularity (any glomeruli); S1, segmental glomerulosclerosis (any glomeruli); TO, tubular atrophy/interstitial fibrosis ( $<25 \%$ of cortical area) $\mathrm{T} 1$, tubular atrophy/interstitial fibrosis ( $25 \%-50 \%$ of cortical area); T2, tubular atrophy/interstitial fibrosis ( $>50 \%$ of cortical area); $\mathrm{CO}$, no crescents; $\mathrm{Cl}$, crescents (<one-fourth of glomeruli); C2, crescents (>one-fourth of glomeruli). All patients had endothelial score available; 132 in the methylprednisolone group and 123 in the placebo group had mesangial hypercellularity, segmental glomerulosclerosis, and tubular atrophy/interstitial fibrosis lesion scores available. For the crescent lesions, data were not available for 7 patients.

e Patients receiving the specified proportion of the maximum labeled dose according to the product information. respectively, reaching ESKD $(P=.10)$. A prespecified subgroup analysis did not show evidence of significant differences in the effects of methylprednisolone on the composite kidney failure outcome in subgroups defined by baseline proteinuria ( $<3.0 \mathrm{vs} \geq 3.0 \mathrm{~g} / \mathrm{d}$ ), kidney function (eGFR $<50$ vs $\geq 50 \mathrm{~mL} / \mathrm{min} / 1.73 \mathrm{~m}^{2}$ ), histological lesion scoring (E1 vs EO by Oxford classification), and dose of angiotensin-converting enzyme inhibitors or angiotensin II receptor blockers (eFigure 2B in Supplement 2) but was limited by the small number of primary outcomes.
The effects on secondary outcomes are listed in Table 3. Only 14 participants reached ESKD, with no clear difference between the randomized groups. Of these participants, 7 had a baseline eGFR less than $30 \mathrm{~mL} / \mathrm{min} / 1.73 \mathrm{~m}^{2}$, and another 4 had baseline eGFR between 30 and $50 \mathrm{~mL} / \mathrm{min} / 1.73 \mathrm{~m}^{2}$. The effects on other components of the primary outcome were directionally similar but not statistically significant. Participants randomized to corticosteroid therapy had a lower risk of composite outcomes, including ESKD, all-cause death, and either 25\% (risk difference, $22.6 \%$ [95\% CI, $12.1 \%$ to $32.6 \%$ ]; 


\begin{tabular}{|c|c|c|c|c|c|}
\hline \multirow[b]{2}{*}{ Outcome } & \multicolumn{2}{|c|}{$\begin{array}{l}\text { Methylprednisolone } \\
(\mathrm{n}=136)\end{array}$} & \multicolumn{2}{|c|}{$\begin{array}{l}\text { Placebo } \\
(\mathrm{n}=126)\end{array}$} & \multirow[b]{2}{*}{$P$ Value $^{\mathrm{a}}$} \\
\hline & Patients & Events & Patients & Events & \\
\hline Total SAEs ${ }^{\mathrm{b}}$ & 20 & 28 & 4 & 4 & .001 \\
\hline SAEs of infection ${ }^{c}$ & 11 & 13 & 0 & 0 & $<.001$ \\
\hline Respiratory infection & & 4 & & 0 & \\
\hline Pneumoncystis pneumonia & & 3 & & 0 & \\
\hline Cryptococcal meningitis & & 1 & & 0 & \\
\hline Nocardia infection of skin and knee joint & & 1 & & 0 & \\
\hline Perianal abscess & & 1 & & 0 & \\
\hline Urinary tract infection & & 1 & & 0 & \\
\hline Fever & & 1 & & 0 & \\
\hline Gastrointestinal SAEs $^{\mathrm{d}}$ & 4 & 4 & 1 & 1 & .62 \\
\hline Duodenal ulcer & & 1 & & 0 & \\
\hline Gastrointestinal bleeding & & 2 & & 0 & \\
\hline Gastric perforation & & 1 & & 1 & \\
\hline SAEs of bone disorders & 3 & 3 & 0 & 0 & \\
\hline Avascular necrosis $^{\mathrm{e}}$ & & 2 & & 0 & .12 \\
\hline Osteochondroma & & 1 & & 0 & \\
\hline Other SAEs ${ }^{f}$ & 5 & 8 & 3 & 3 & .22 \\
\hline Pulmonary embolism & & 1 & & 0 & \\
\hline Deep vein thrombosis & & 2 & & 0 & \\
\hline Hepatotoxicity & & 1 & & 0 & \\
\hline Hemoptysis & & 1 & & 0 & \\
\hline Acute right upper quadrant pain & & 1 & & 0 & \\
\hline Arthralgia & & 1 & & 0 & \\
\hline Symptomatic incarcerated paraumbilical hernia & & 0 & & 1 & \\
\hline Uremia & & 0 & & 2 & \\
\hline Soft tissue injury & & 1 & & 0 & \\
\hline Adverse events of special interest & 4 & 4 & 3 & 3 & \\
\hline New-onset diabetes mellitus & & 2 & & 3 & 67 \\
\hline Avascular necrosis ${ }^{\mathrm{e}}$ & & 1 & & 0 & \\
\hline Fracture ${ }^{\mathrm{e}}$ & & 1 & & 0 & \\
\hline
\end{tabular}

Figure 2. Time From Randomization to First Serious Adverse Event, by Treatment Group

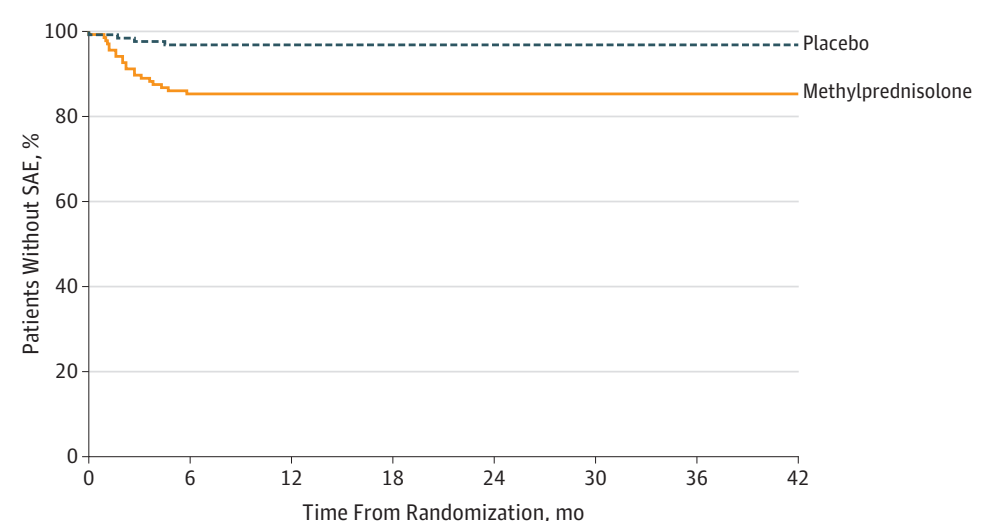

No. at risk

$\begin{array}{lrrrrrrrr}\text { Methylprednisolone } & 136 & 116 & 115 & 106 & 94 & 71 & 51 & 33\end{array}$
Abbreviation: SAE, serious adverse event.

${ }^{\text {a }}$ Comparison of proportion of patients with at least 1 event using Fisher exact test.

${ }^{\mathrm{b}}$ Five patients had more than 1SAE.

${ }^{\mathrm{C}}$ Two patients had more than 1SAE of infection.

d One patient had 1 gastrointestinal 1 infection, and 1 other SAE.

e Two patients with avascular necrosis were reported as having SAEs; 1 patient with avascular necrosis and 1 with fracture were reported as having adverse events of special interest. $P$ values obtained by combining these events.

${ }^{f}$ One patient had 4 other SAEs.
Median at-risk duration of follow-up was 19.7 (interquartile range, 9.2-30.1) months for methylprednisolone and 25.2 (interquartile range, 14.8-32.7) months for placebo. Relative risk, 4.63 ( $95 \% \mathrm{Cl}, 1.63-13.2)$; $P=.001$ by Fisher exact test. SAE indicates serious adverse event.
$P<.001$ ) or $40 \%$ (risk difference, $8.5 \%$ [95\% CI, 0.7\% to $16.6 \%$ ]; $P=.03)$ reductions in eGFR, but not composite outcomes including a 50\% reduction in eGFR $(P=.29)$.
The mean annual rate of eGFR decline in the methylprednisolone group was $-1.79 \mathrm{~mL} / \mathrm{min} / 1.73 \mathrm{~m}^{2}$, compared with $-6.95 \mathrm{~mL} / \mathrm{min} / 1.73 \mathrm{~m}^{2}$ in the placebo group (difference, 5.15 
Figure 3. Time From Randomization to First Primary Composite Outcome of $40 \%$ eGFR Decrease, ESKD, or Death Due to Kidney Failure, by Treatment Group

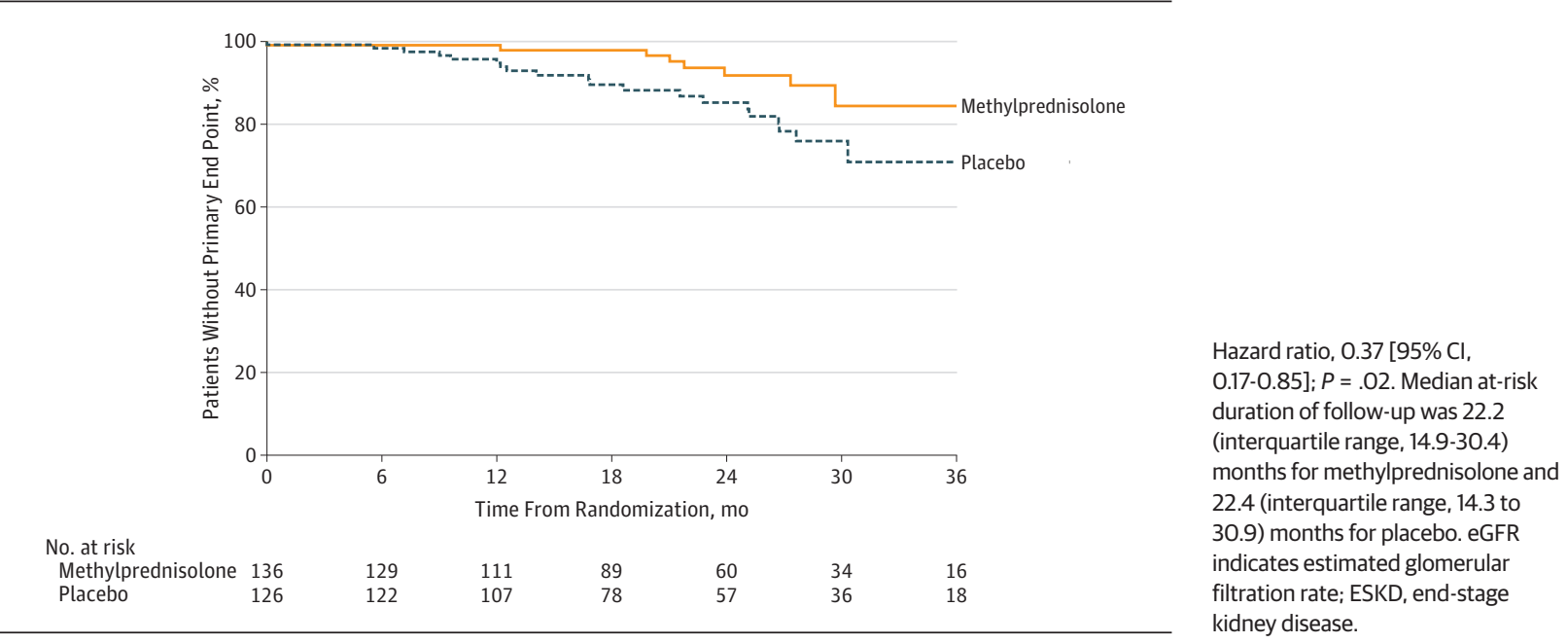

[95\% CI, 0.42 to 9.89 ] $\left.\mathrm{mL} / \mathrm{min} / 1.73 \mathrm{~m}^{2} ; P=.03\right)$. A prespecified sensitivity analysis excluding the treatment period with highest corticosteroid exposure (from month 1 to $3,-0.11$ vs $-6.38 \mathrm{~mL} / \mathrm{min} / 1.73 \mathrm{~m}^{2}$; risk difference, 6.27 [95\% CI, 2.77 to 9.76 ] $\left.\mathrm{mL} / \mathrm{min} / 1.73 \mathrm{~m}^{2} ; P<.001\right)$ and the entire treatment exposure period (from month 1 to $6,-1.64$ vs $-5.64 \mathrm{~mL} / \mathrm{min} / 1.73 \mathrm{~m}^{2}$; risk difference, 4.00 [95\% CI, 1.22 to $\left.6.78] \mathrm{mL} / \mathrm{min} / 1.73 \mathrm{~m}^{2} ; P=.005\right)$ showed similar results. Analyses using annual change of inverse of serum creatinine level instead of eGFR showed similar results. The eGFR in the corticosteroid-treated group increased early and remained significantly higher than in the placebo-treated group at each study visit, to 3 years of follow-up (Figure $4 \mathrm{~A}$ ). The overall mean difference (methylprednisolone - placebo) in eGFR over the entire follow-up (months 3-36) was $6.1 \mathrm{~mL} / \mathrm{min} / 1.73 \mathrm{~m}^{2}$ (95\% CI, 2.9 to $9.3 ; P<.001)$.

Mean proteinuria during follow-up was significantly reduced in the methylprednisolone-treated group (1.37 [SD, 1.08] vs 2.36 (SD, 1.67) g/d; difference, $-0.99 \mathrm{~g} / \mathrm{d}$ [95\% CI, -1.34 to $-0.64 \mathrm{~g} / \mathrm{d}] ; P<.001$ ) (Figure 4B). This was consistent with the overall difference estimated with linear mixed models (difference, $-1.0 \mathrm{~g} / \mathrm{d}$ [95\% CI, -1.36 to -0.65 ]; $P<.001)$. The proportion of individuals achieving either complete or partial remission of proteinuria at 6 months was $45.1 \%$ in the corticosteroid group vs 13.7\% in the placebo group (risk difference, 31.4\% [95\% CI, $18.9 \%$ to $42.5 \%$ ]; $P<.001$ ), with similar results at 12 months (52.2\% vs $13.6 \%$; risk difference, $38.5 \%$ [95\% CI, $25.2 \%$ to $50.0 \%$ ]; $P$ < .001) and 24 months (48.2\% vs $21.8 \%$; risk difference, $26.4 \%$ [95\% CI, $8.7 \%$ to $42.0 \%$ ]; $P=.005$ ). At 6 months, the rates of complete remission of proteinuria were $7.8 \%$ for the corticosteroid group vs $1.1 \%$ for the placebo group (risk difference, $6.8 \%$ [95\% CI, $0.8 \%$ to $13.6 \%$ ]; $P=.04$ ) and of partial remission were $45.1 \%$ vs $13.7 \%$ (risk difference, $31.4 \%$ [95\% CI, $18.9 \%$ to $42.5 \%$ ]; $P<.001$ ). Microscopic hematuria (defined as at least 5 red blood cells per high-power field) was noted in 138 patients (62.2\%) at baseline. Among those, 127 had at least 1 subsequent measurement, with 61 (48.0\%) showing remission by the last visit. This occurred in $58.8 \%$ of participants in the methylprednisolone group vs 35.6\% in the placebo group (risk difference, $23.2 \%$ [95\% CI, 5.8\% to $38.7 \%$ ]; $P=.01$ ).

\section{Discussion}

This study assessed a full-dose corticosteroid regimen in patients with IgA nephropathy at high risk and found high rates of serious adverse outcomes due mainly to an increased risk of serious infections, resulting in the early cessation of recruitment to the trial. While proteinuria and eGFR levels were improved, and suggestions of potential benefit for the primary outcome were observed, there were too few primary outcomes to draw definitive conclusions about treatment efficacy from this trial.

The nearly 5 times higher risk of SAEs is a particularly important finding, given that many previous corticosteroid trials in IgA nephropathy have collected and reported adverse effects inconsistently. ${ }^{9}$ It is possible that the high rate of infections was related to the trial population or the specific treatment regimen used in this study; however, the Supportive Versus Immunosuppressive Therapy for the Treatment of Progressive IgA Nephropathy (STOP-IgAN) trial also collected and reported detailed adverse-event data and found similarly high rates of severe infections among the immunosuppression group (8.1\% vs $9.8 \%$ ), including 1 death in the combination immunosuppression group. ${ }^{13}$ The excess of SAEs (mostly infections) observed in this study has implications for clinical decision making and treatment guidelines for the use of corticosteroids in IgA nephropathy. Future studies could also consider the use of prophylactic antibiotic therapy, which has not been used in any of the completed studies and is not recommended in clinical practice guidelines.

While interpretation of the primary results is limited, the findings are consistent with a meta-analysis of 9 smaller trials, which found that corticosteroid therapy was associated with a lower risk of composite renal outcomes (50\% reduction in eGFR or ESKD; relative risk, 0.32 [95\% CI, 0.15 to 0.67]). ${ }^{19}$ 


\begin{tabular}{|c|c|c|c|c|}
\hline Outcome & $\begin{array}{l}\text { Methylprednisolone } \\
(\mathrm{n}=136)\end{array}$ & $\begin{array}{l}\text { Placebo } \\
(n=126)\end{array}$ & $\begin{array}{l}\text { Absolute Difference } \\
(95 \% \mathrm{Cl})\end{array}$ & $P$ Value $^{\mathrm{a}}$ \\
\hline \multicolumn{5}{|l|}{ Primary outcome, No. (\%) } \\
\hline $\begin{array}{l}\text { 40\% eGFR decrease, ESKD, or death } \\
\text { due to kidney failure }\end{array}$ & $8(5.9)$ & $20(15.9)$ & $10.0(2.5$ to 17.9$)$ & .02 \\
\hline \multicolumn{5}{|l|}{ Protocol-specified secondary outcomes } \\
\hline $\begin{array}{l}\text { 40\% eGFR decrease, ESKD, or all-cause death, } \\
\text { No. }(\%)\end{array}$ & $10(7.4)$ & $20(15.9)$ & $8.5(0.7$ to 16.6$)$ & .03 \\
\hline $\begin{array}{l}\text { 50\% eGFR decrease, ESKD, or all-cause death, } \\
\text { No. (\%) }\end{array}$ & $10(7.4)$ & $15(11.9)$ & $4.6(2.7$ to 12.1$)$ & .29 \\
\hline 40\% eGFR decrease, №. (\%) & $7(5.1)$ & $16(12.7)$ & $7.6(0.6$ to 15.0$)$ & .05 \\
\hline $50 \%$ eGFR decrease, No. (\%) & $7(5.1)$ & $11(8.7)$ & $3.6(2.8$ to 10.3$)$ & .33 \\
\hline ESKD or death due to kidney failure, №. (\%) ${ }^{\mathrm{b}}$ & $4(2.9)$ & $10(7.9)$ & $5.0(0.7$ to 11.3$)$ & .10 \\
\hline Death due to any cause, No. (\%) & $2(1.5)$ & $1(0.8)$ & 0.7 ( -0.3 to 0.4 to $)$ & $>.99$ \\
\hline $\begin{array}{l}\text { Rate of eGFR decline using all visits, } \\
\text { mean }(95 \% \mathrm{Cl}), \mathrm{mL} / \mathrm{min} / 1.73 \mathrm{~m}^{2 \mathrm{c}}\end{array}$ & $-1.79(-4.74$ to 1.16$)$ & $-6.95(-10.68$ to -3.21$)$ & $5.15(0.42$ to 9.89$)$ & .03 \\
\hline $\begin{array}{l}\text { Rate of eGFR decline excluding values } \\
\text { on high-exposure treatment, } \\
\text { mean }(95 \% \mathrm{Cl}), \mathrm{mL} / \mathrm{min} / 1.73 \mathrm{~m}^{2 \mathrm{~d}}\end{array}$ & $-0.11(-2.52$ to 2.30$)$ & $-6.38(-8.93$ to -3.82$)$ & $6.27(2.77$ to 9.76$)$ & $<.001$ \\
\hline $\begin{array}{l}\text { Rate of eGFR decline excluding values on treatment, } \\
\text { mean }(95 \% \mathrm{CI}), \mathrm{mL} / \mathrm{min} / 1.73 \mathrm{~m}^{\mathrm{b} b \text {, }}\end{array}$ & $-1.64(-3.33$ to 0.05$)$ & $-5.64(-7.86$ to -3.41$)$ & $4.00(1.22$ to 6.78$)$ & .005 \\
\hline Time-averaged proteinuria, mean $(95 \% \mathrm{Cl}), \mathrm{g} / \mathrm{d}$ & 1.37 (1.18 to 1.56$)$ & $2.36(2.06$ to 2.66$)$ & $-0.99(-1.34$ to -0.64$)$ & $<.001$ \\
\hline \multicolumn{5}{|l|}{ Prespecified exploratory outcomes } \\
\hline $\begin{array}{l}\text { 25\% eGFR decrease, ESKD, or all cause death, } \\
\text { No. (\%) }\end{array}$ & $20(14.7)$ & $47(37.3)$ & $22.6(12.1$ to 32.6$)$ & $<.001$ \\
\hline 25\% eGFR decrease, No. (\%) & $17(12.5)$ & $44(34.9)$ & $22.4(12.2-32.2)$ & $<.001$ \\
\hline $\begin{array}{l}\text { Yearly decline in } 1 / \text { creatinine using all visits, } \\
\text { mean }(95 \% \mathrm{Cl}), \mathrm{mg}^{\mathrm{d} \mathrm{dL}^{\mathrm{f}}}\end{array}$ & $-0.03(-0.07$ to 0.01$)$ & $-0.07(-0.11$ to -0.03$)$ & $0.04(-0.01$ to 0.10$)$ & .16 \\
\hline $\begin{array}{l}\text { Yearly decline in } 1 / \text { creatinine excluding values } \\
\text { on high-exposure treatment, mean }(95 \% \mathrm{Cl}), \mathrm{mg} / \mathrm{dL}^{\mathrm{g}}\end{array}$ & $-0.00(-0.03$ to 0.02$)$ & $-0.07(-0.10$ to -0.04$)$ & 0.06 (0.02 to 0.11$)$ & .002 \\
\hline $\begin{array}{l}\text { Yearly decline in } 1 / \text { creatinine excluding values } \\
\text { on treatment, mean }(95 \% \mathrm{Cl}), \mathrm{mg} / \mathrm{dL}^{\mathrm{h}}\end{array}$ & $-0.01(-0.04$ to 0.01$)$ & $-0.06(-0.08$ to -0.04$)$ & 0.04 (0.01 to 0.07 & .003 \\
\hline \multicolumn{5}{|l|}{ Total proteinuria remission, No./total (\%) } \\
\hline Month 6 & $46 / 102(45.1)$ & $13 / 95(13.7)$ & $31.4(18.9$ to 42.5$)$ & $<.001$ \\
\hline Month 12 & $48 / 92(52.2)$ & $12 / 88(13.6)$ & $38.5(25.2$ to 50.0$)$ & $<.001$ \\
\hline Month 24 & $27 / 56(48.2)$ & $12 / 55(21.8)$ & 26.4 (8.7 to 42.0$)$ & .005 \\
\hline $\begin{array}{l}\text { Disappearance of hematuria at last visit, } \\
\text { No./total }(\%)^{j}\end{array}$ & $40 / 68(58.8)$ & $21 / 59(35.6)$ & $23.2(5.8$ to 38.7$)$ & .01 \\
\hline \multicolumn{2}{|c|}{$\begin{array}{l}\text { Abbreviations: eGFR, estimated glomerular filtration rate; ESKD, end-stage } \\
\text { kidney disease. }\end{array}$} & \multicolumn{3}{|c|}{$\begin{array}{l}{ }^{f} \text { Defined for each individual patient using the slope from least-squares linear } \\
\text { regression of all reciprocal of serum creatinine values over time. }\end{array}$} \\
\hline \multicolumn{2}{|c|}{$\begin{array}{l}\text { a } P \text { value for primary outcome calculated using survival analysis. Other } P \text { values } \\
\text { calculated using } t \text { tests or Fisher exact tests. }\end{array}$} & \multicolumn{3}{|c|}{$\begin{array}{l}{ }^{\mathrm{g}} \text { Defined as above but excluding the treatment period with highest } \\
\text { corticosteroid exposure from month } 1 \text { and month } 3 \text {. }\end{array}$} \\
\hline \multicolumn{2}{|c|}{ b No deaths due to kidney failure were observed in the trial. } & \multicolumn{3}{|c|}{$\begin{array}{l}\text { h Defined as above but excluding the treatment period with corticosteroid } \\
\text { exposure from months } 1,3 \text {, and } 6 \text {. }\end{array}$} \\
\hline \multicolumn{2}{|c|}{$\begin{array}{l}\text { ' } \text { Defined for each individual patient using the slope from least-squares linear } \\
\text { regression of all eGFR estimates over time. }\end{array}$} & \multirow{2}{*}{\multicolumn{3}{|c|}{$\begin{array}{l}\text { i Total proteinuria remission is defined as complete or partial remission. } \\
\text { Complete proteinuria remission is defined as } 24 \text {-hour urinary protein less than } \\
200 \mathrm{mg} / \mathrm{d} \text { and partial proteinuria remission as proteinuria less than } 50 \% \text { of } \\
\text { baseline by } 24 \text {-hour urinary protein and less than } 1 \mathrm{~g} / \mathrm{d} \text {. }\end{array}$}} \\
\hline $\begin{array}{l}\text { dDefined as above, but excluding the treatment period } \mathrm{v} \\
\text { corticosteroid exposure from month } 1 \text { and month } 3 \text {. }\end{array}$ & rith highest & & & \\
\hline \multicolumn{2}{|c|}{$\begin{array}{l}\text { e Defined as above, but excluding the treatment period with highest } \\
\text { corticosteroid exposure from months } 1,3 \text {, and } 6 \text {. }\end{array}$} & \multicolumn{3}{|c|}{$\begin{array}{l}{ }^{j} \text { Defined as urinalysis revealing less than } 5 \text { red blood cells per high-power field } \\
\text { at the end of the study or last available visit for those participants with } \\
\text { microhematuria or macrohematuria at randomization visit. }\end{array}$} \\
\hline
\end{tabular}

These findings contrast with those from the STOP-IgAN study, which randomized 162 participants to immunosuppression or supportive therapy alone for 3 years and found no effect on slope of eGFR decline or ESKD. ${ }^{13}$ Possible reasons for the difference in results include the fact that participants in the present trial were at higher risk because of higher mean baseline proteinuria levels and perhaps also because individuals of Eastern Asian origin (eg, China, Japan, Philippines, and Vietnam) may have more rapid rates of eGFR decline and kidney failure. ${ }^{20}$ The rate of eGFR loss among patients in the supportive-therapy group of this study was higher than that in STOP-IgAN (-6.95 vs
$-1.6 \mathrm{~mL} / \mathrm{min} / 1.73 \mathrm{~m}^{2}$ per year), making detection of any benefit more likely. The annual rate of eGFR decline in STOP-IgAN was also lower than that observed in a cohort study ${ }^{21}$ and a recent trial, ${ }^{22}$ both from Europe. The longer period of RAS blockade in STOP-IgAN is another difference; however, the rate of eGFR loss in the placebo group did not slow appreciably with longer RAS exposure time during follow-up in the TESTING placebo group, and the effects did not differ by dose of RAS blockade. Although ethnic differences in response to treatment are possible, this is not suggested by the results of previous trials. ${ }^{9}$ The shorter follow-up of the present trial compared with the STOP IgAN trial 
Figure 4. Effect of Methylprednisolone Therapy on eGFR and Proteinuria During Follow-up

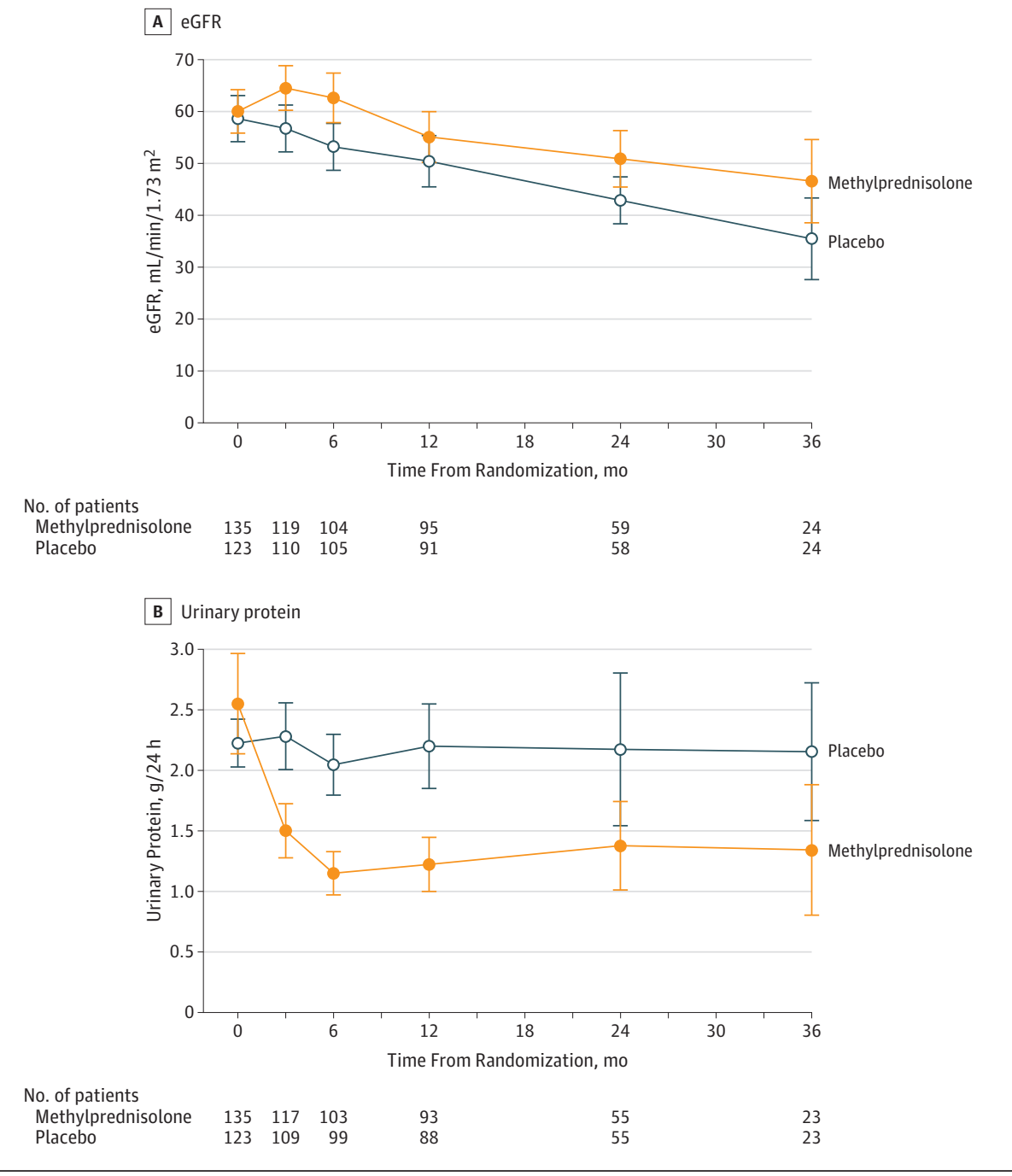

Randomization proteinuria and estimated glomerular filtration rate (eGFR) data are not available for 4 participants who were therefore excluded from this analysis. Error bars indicate $95 \%$ confidence intervals. $A$, Mean difference in eGFR was 5.14 ( $95 \% \mathrm{Cl}, 1.90$ to 8.37$)$ $\mathrm{mL} / \mathrm{min} / 1.73 \mathrm{~m}^{2}$ at month 3; $6.74(95 \% \mathrm{Cl}, 3.40$ to 10.09$)$ $\mathrm{mL} / \mathrm{min} / 1.73 \mathrm{~m}^{2}$ at month $6 ; 4.62$ ( $95 \% \mathrm{Cl}, 1.16$ to 8.09$) \mathrm{mL} / \mathrm{min} / 1.73 \mathrm{~m}^{2}$ at month $12 ; 5.43(95 \% \mathrm{Cl}, 1.37$ to 9.48) $\mathrm{mL} / \mathrm{min} / 1.73 \mathrm{~m}^{2}$ at month 24 ; and $7.67(95 \% \mathrm{Cl}, 1.91$ to 13.43$)$ $\mathrm{mL} / \mathrm{min} / 1.73 \mathrm{~m}^{2}$ at month $36(P<.01$ for all). The annual rate of eGFR decline was lower in the methylprednisolone group (-1.79 vs $-6.95 \mathrm{~mL} / \mathrm{min} / 1.73 \mathrm{~m}^{2}$ per year; mean difference, 5.15 [ $95 \% \mathrm{Cl}, 0.42$ to 9.89]; $P=.03)$. B, Mean difference in proteinuria was $-0.83(95 \% \mathrm{Cl},-1.18$ to -0.47$) \mathrm{g} / \mathrm{d}$ at month $3 ;-1.00$ (95\% $\mathrm{Cl},-1.37$ to -0.63$) \mathrm{g} / \mathrm{d}$ at month 6 ; $-1.20(95 \% \mathrm{Cl},-1.59$ to -0.81$) \mathrm{g} / \mathrm{d}$ at month $12 ;-1.03(95 \% \mathrm{Cl},-1.49$ to $-0.56) \mathrm{g} / \mathrm{d}$ at month 24 ; and -0.93 $(95 \% \mathrm{Cl},-1.60$ to -0.25$) \mathrm{g} / \mathrm{d}$ at month $36(P<.01$ for all). Time-averaged proteinuria was significantly lower in the methylprednisolone group than in the placebo group $(1.37 \mathrm{vs} 2.36 \mathrm{~g} / \mathrm{d}$; mean difference, $-0.99[95 \% \mathrm{Cl}$, -1.34 to -0.64$] ; P<.001)$. is another possible reason. Ongoing follow-up of both studies is important to better define the longer-term kidney effects, particularly as the adverse events mostly occurred early, whereas the benefits appeared to accrue throughout follow-up.

The early increase in eGFR observed in the corticosteroidtreated participants raises the possibility that some of the eGFR effects may be due to sarcopenic effects of corticosteroid leading to reduced creatinine generation (eFigure 3 in Supplement 2) or due to corticosteroid-induced hyperfiltration. ${ }^{23,24} \mathrm{Ex}^{-}$ cluding the creatinine measures during the treatment period attenuated the difference in the rate of eGFR loss over time, but it remained significantly lower in the corticosteroidtreated group. The early reduction in proteinuria, as well as the difference in rates of the more clinically important primary outcome, suggest that potentially clinically important benefits are possible, which will be further clarified by the ongoing follow-up of study participants.

Strengths of this trial include the relatively large sample size. The ongoing participant follow-up will help to more accurately assess the efficacy of corticosteroids. This study also has several limitations. Although to our knowledge this is the largest trial reported to date among patients with IgA nephropathy, recruitment was stopped earlier than planned because of excess adverse events, so power was less than predicted, and both risks and benefits might be overestimated as a result. Most participants were of a single ethnicity, meaning ethnicity-based treatment responses cannot be assessed. The reliance on eGFR based on serum creatinine measurement is another limitation, particularly because corticosteroids may reduce creatinine generation.

\section{Conclusions}

Among patients with IgA nephropathy and proteinuria greater than $1 \mathrm{~g} / \mathrm{d}$, oral methylprednisolone was associated with an increased risk of serious adverse events, primarily infections. Although the results are consistent with potential benefit, definitive conclusions about treatment benefit cannot be made, owing to early termination of the trial. 


\section{ARTICLE INFORMATION}

Accepted for Publication: June 29, 2017.

Author Affiliations: Renal Division, Department of Medicine, Peking University First Hospital, Beijing, China (Lv, Zhang, Zhao, Wang); The George Institute for Global Health, University of New South Wales, Sydney, Australia (Lv, Wong, Jardine, Monaghan, Woodward, Billot, Cass, Perkovic); Sunnybrook Health Sciences Centre, Toronto, Ontario, Canada (Hladunewich); The George Institute for Global Health, New Delhi, India (Jha); University of Oxford, Oxford, United Kingdom (Jha); The University of British Columbia, Vancouver, British Columbia, Canada (Barbour, Levin); University Health Network, Toronto, Ontario, Canada (Reich, Cattran); David Geffen School of Medicine, University of California-Los Angeles (Glassock); Royal Free and University College Medical School, London, United Kingdom (Wheeler); The George Institute for Global Health, University of Oxford, Oxford, United Kingdom (Woodward); Department of Epidemiology, Johns Hopkins University, Baltimore, Maryland (Woodward); University of Hong Kong, Hong Kong, China (Chan); Research Institute of Nephrology, Jinling Hospital, Nanjing, China (Liu); Australasian Kidney Trials Network, University of Queensland, Brisbane, Australia (Johnson); Menzies School of Health Research, Charles Darwin University, Darwin, Australia (Cass); University of Leicester, Leicester, United Kingdom (Feehally); Division of Nephrology and Clinical Immunology, RWTH Aachen University, Aachen, Germany (Floege); Mario Negri Institute for Pharmacological Research and Clinical Research Centre for Rare Diseases, Bergamo, Italy (Remuzzi); Peking University Clinical Research Institute, Beijing, China (Wu); Indiana University School of Medicine, Indianapolis (Agarwal).

Author Contributions: Drs Perkovic and Zhang had full access to all of the data in the study and take responsibility for the integrity of the data and the accuracy of the data analysis.

Concept and design: Lv, Zhang, Jardine, Monaghan, Barbour, Reich, Cattran, Glassock, Levin, Wheeler, Chan, Johnson, Cass, Feehally, Floege, Remuzzi, Wu, Wang, Perkovic.

Acquisition, analysis, or interpretation of data: LV, Zhang, Wong, Jardine, Hladunewich, Jha, Zhao, Barbour, Cattran, Glassock, Woodward, Billot, Chan, Liu, Johnson, Aggarwal, Perkovic. Drafting of the manuscript: Lv, Zhang, Wong, Monaghan, Wheeler, Liu, Johnson, Wang, Perkovic. Critical revision of the manuscript for important intellectual content: Lv, Zhang, Wong, Jardine, Hladunewich, Jha, Zhao, Barbour, Reich, Cattran, Glassock, Levin, Wheeler, Woodward, Billot, Chan, Johnson, Cass, Feehally, Floege, Remuzzi, Wu, Aggarwal, Perkovic.

Statistical analysis: Woodward, Billot. Obtained funding: Zhang, Hladunewich, Reich, Cattran, Cass, Perkovic.

Administrative, technical, or material support: Lv, Zhang, Wong, Jardine, Jha, Monaghan, Reich, Cattran, Levin, Liu, Wu, Perkovic. Supervision: Lv, Zhang, Wong, Jardine, Jha, Zhao, Barbour, Glassock, Wheeler, Chan, Johnson, Cass, Floege, Aggarwal, Wang, Perkovic.

Conflict of Interest Disclosures: All authors have completed and submitted the ICMJE Form for
Disclosure of Potential Conflicts of Interest. Dr Lv reported receiving grant funding from Pfizer. Dr Zhang reported receiving grant funding from Peking University Health Central Clinical Research Project and Pfizer during the conduct of the study and receiving personal fees for steering committee membership from Janssen. Dr Wong reported receiving grant funding from the Diabetes Australia Research Trust and giving scientific presentation supported by Astra Zeneca, Roche, and Amgen. Dr Jardine reported receiving grant funding from the National Health and Medical Research Council of Australia and the National Heart Foundation, Cardiovascular Research Network, Gambro, Amgen, Eli Lilly, Merck, Rebecca L. Cooper Medical Research Foundation grant and KHA Project grant; and receiving fees from Boehringer Ingelheim, Fresenius, and Amgen directed to clinical research programs. Dr Hladunewich reported receiving grants from the Canadian Institute of Health Research. Dr Jha reported receiving grant funding from Baxter Healthcare and GSK. Dr Barbour reported receiving grants from the Canadian Institute of Health Research. Dr Reich reported receiving grants and personal fees from Amgen. Dr Cattran reported receiving unrestricted research funding from Genentech; grant funding from the Canadian Institutes of Health; research funding and personal support from the National Institute of Diabetes and Digestive and Kidney Diseases; personal funding for serving on scientific advisory board from Chemocentryx, Omerus, Mallinckrodt; and serving without compensation on the scientific board of Nephcure. Dr Woodward reported receiving personal fees from Amgen. Dr Wheeler reported receiving honoraria from Akebia, Astra Zeneca, Amgen, Boehringer Ingelheim, Janssen, and Vifor Fresenius Medical Care. Dr Johnson reported receiving grant funding from Baxter Healthcare, Fresenius Medical Care, and the National Health and Medical Research Council of Australia; and receiving personal fees from Baxter Healthcare, Fresenius Medical Care, and Astra Zeneca. Dr Floege reported consulting on IgA nephropathy for Pharmalink, Omeros, and Chugai and giving scientific presentations supported by Amgen and Vifor. Dr Remuzzi reported receiving personal fees from Janssen Research and Development. Dr Agarwal reported receiving personal fees from Janssen, Boehringer Ingelheim, Relypsa, Opko, Astra Zeneca, Amgen, Sanofi, Akebia, Bayer, and UpToDate. Dr Perkovic reported consulting on IgA nephropathy for Pharmalink, Eli Lilly, and Novartis; giving scientific presentations supported by Pfizer; and having a policy of honoraria being paid to his institution.

\section{Group Information: TESTING Steering} Committee: Cochairs: Hong Zhang, Peking University Institute of Nephrology, China; Vlado Perkovic, The George Institute for Global Health, Australia; Hai-Yan Wang, Peking University Institute of Nephrology, China (deceased). Members: Michelle Hladunewich, Sunnybrook Health Sciences Centre, Canada; Vivek Jha, The George Institute for Global Health, India; The Postgraduate Institute of Medical Education and Research, India; Jicheng Lv, Peking University and The George Institute for Global Health, China; Helen Monaghan, The George Institute for Global Health, Australia; Muh Geot Wong, The George Institute for Global Health, Australia; Sean Barbour, The University of British
Columbia, Vancouver, Canada; Alan Cass, The George Institute for Global Health, Australia; Menzies School of Health Research, Charles Darwin University, Australia; Daniel Cattran, University Health Network, Canada; Tak Mao Chan, University of Hong Kong, China; John Feehally, University of Leicester, United Kingdom; Jürgen Floege, University of Aachen, Germany; Richard J. Glassock, UCLA David Geffen School of Medicine, Los Angeles, California; Meg Jardine, The George Institute for Global Health, Australia; David Johnson, Australasian Kidney Trials Network, Australia; Adeera Levin, the University of British Columbia, Canada; Zhihong Liu, Nanjing University School of Medicine, China; Heather Reich, University Health Network, Canada; Giuseppe Remuzzi, Mario Negri Institute for Pharmacological Research and Clinical Research Centre for Rare Diseases, Italy; David Wheeler, Royal Free and University College Medical School, United Kingdom; Mark Woodward, The George Institute for Global Health, Australia, and Department of Epidemiology, Johns Hopkins University, Baltimore, Maryland; Yangfeng Wu, Peking University, China; Minghui Zhao, Peking University Institute of Nephrology, China; Rajiv Agarwal, Indiana University School of Medicine, Indianapolis. Data and Safety Monitoring Committee: David Jayne (chair), Tom Greene, Mike Walsh, Angela Wang. End Point Adjudication Committee: Rajiv Agarwal (chair), Li Zuo, Amanda Mather, Amanda Wang. Global Coordinating Centre: Helen Monaghan (project manager), Rebecca Anderson, Jicheng Lv, Muh Geot Wong, Dominic Byrne (senior data manager), Laurent Billot, Sandrine Stepien, Jayanthi Mysore (statisticians), Hong Zhang, Vlado Perkovic. Endorsement: Australasian Kidney Trials Network. Study Sites: China: Jicheng Lv, Peking University First Hospital; Zhangsuo Liu, The First Affiliated Hospital of Zhengzhou University; Caili Wang, First Affiliated Hospital of Inner Mongolia, Baotou Medical College; Shuxia Fu, The Second Hospital of Hebei Medical University; Jinghong Zhao, Xinqiao Hospital, Third Military Medical University; Lihua Wang, The Second Affiliated Hospital of Shanxi Medical University; Zhaohui Ni, Renji Hospital, Shanghai Jiaotong University School of Medicine; Nan Chen, Ruijin Hospital, Shanghai Jiaotong University, School of Medicine; Haitao Zhang, Nanjing General Hospital of Nanjing Military Command; Qiong Luo, Peking University Shenzhen Hospital; Mei Wang, Peking University People's Hospital; Rong Wang, Provincial Hospital Affliated to Shandong University; Peng Li , Yantai Yuhuangding Hospital; Jianghua Chen, The First Affiliated Hospital of Zhejiang University of Medicine; Guangyan Cai, The Chinese PLA General Hospital; Ping Fu, West China Hospital of Sichuan University; Chun Zhang, Union Hospital, Tongji Medical College, Huazhong University of Science and Technology; Guisen Li, Sichuan Academy of Medical Science and Sichuan Provincial People's Hospital; Detian Li, Shengjing Hospital of China Medical University; Dongmei Xu, Qianfoshan Hospital Affiliated to Shandong University; Guohua Ding, Renmin Hospital, Wuhan University; Hongyu Chen, Hangzhou Chinese Medicine Hospital; Zhao $\mathrm{Hu}$, Qilu Hospital of Shandong University; Zhiling Guo, First Affiliated Hospital of Henan University of Science and Technology; Fuming Lu, Huashan Hospital, Affiliated to Fudan University; Aiping Zhang, Jinan General Hospital of PLA; Beiyan Bao, 
Ningbo Urinary Kidney Disease Hospital; Qiang He Zhejiang Provincial People's Hospital; Yue Wang, Beijing University Third Hospital; Li Gong, Inner Mongolia People's Hospital; Ying Li, The Third Hospital of Hebei Medical University; Bing Liu, Henan Provincial People's Hospital; Yipu Shen, Beijing Anzhen Hospital affiliated to Beijing Capital Medical University; Gang Xu, Tongji Hospital of Huazhong University of Science and Technology: Changying Xing, The First Affiliated Hospital with Nanjing Medical University (Jiangsu Province Hospital); Wei Shi, Guangdong Province People's Hospital; Xiaoxuan Zhang, Fourth Hospital Affiliated to Jilin University (FAW General Hospital); Hua Wu, Beijing Hospital; Hongli Lin, First Affiliated Hospital of Dalian Medical University; Xueqing Yu, First Affiliated Hospital, Sun Yat-Sen University. Hong Kong: Samual Fung, Princess Margaret Hospital. Australia: Mona Razavian, Concord Repatriation General Hospital; Chen Au Peh, Royal Adelaide Hospital, Kathy Nicholls, Royal Melbourne Hospital; Bruce Cooper, Royal North Shore Hospital; David Johnson, Princess Alexandra Hospital.

Funding/Support: This study was supported by the National Health and Medical Research Council of Australia, the Peking University Health Central Clinical Research Project, and the Canadian Institutes of Health Research. Study drug was provided by Pfizer Pharmaceuticals.

Role of the Funder/Sponsor: The funders/sponsors had no role in the design and conduct of the study; collection, management, analysis, and interpretation of the data; preparation, review, or approval of the manuscript; and decision to submit the manuscript for publication.

Additional Contributions: Hai-Yan Wang, MD is deceased.

REFERENCES

1. Wyatt RJ, Julian BA. IgA nephropathy. N Engl J Med. 2013;368(25):2402-2414.

2. Le W, Liang $S$, Hu Y, et al. Long-term renal survival and related risk factors in patients with IgA nephropathy: results from a cohort of 1155 cases in a Chinese adult population. Nephrol Dial Transplant. 2012;27(4):1479-1485.

3. Reich HN, Troyanov S, Scholey JW, Cattran DC; Toronto Glomerulonephritis Registry. Remission of proteinuria improves prognosis in IgA nephropathy. J Am Soc Nephrol. 2007;18(12):3177-3183.
4. Lv J, Zhang H, Zhou Y, Li G, Zou W, Wang $\mathrm{H}$. Natural history of immunoglobulin A nephropathy and predictive factors of prognosis: a long-term follow up of 204 cases in China. Nephrology (Carlton) 2008:13(3):242-246

5. Coppo R, Peruzzi L, Amore A, et al. IgACE: a placebo-controlled, randomized trial of angiotensin-converting enzyme inhibitors in children and young people with IgA nephropathy and moderate proteinuria. J Am Soc Nephrol. 2007; 18(6):1880-1888.

6. The GISEN Group (Gruppo Italiano di Studi Epidemiologici in Nefrologia). Randomised placebo-controlled trial of effect of ramipril on decline in glomerular filtration rate and risk of terminal renal failure in proteinuric, non-diabetic nephropathy. Lancet. 1997;349(9069):1857-1863.

7. Cattran DC, Feehally J, Cook HT, et al. Kidney disease: Improving Global Outcomes (KDIGO) glomerulonephritis work group: KDIGO clinical practice guideline for glomerulonephritis. Kidney Int Suppl. 2012;2(2):139-274

8. Floege J, Amann K. Primary glomerulonephritides. Lancet. 2016:387(10032):2036-2048.

9. Lv J, Xu D, Perkovic V, et al; TESTING Study Group. Corticosteroid therapy in IgA nephropathy. J Am Soc Nephrol. 2012;23(6):1108-1116.

10. Manno C, Torres DD, Rossini M, Pesce F, Schena FP. Randomized controlled clinical trial of corticosteroids plus ACE-inhibitors with long-term follow-up in proteinuric IgA nephropathy. Nephrol Dial Transplant. 2009;24(12):3694-3701.

11. Lv J, Zhang $\mathrm{H}$, Chen $\mathrm{Y}$, et al. Combination therapy of prednisone and ACE inhibitor versus ACE-inhibitor therapy alone in patients with IgA nephropathy: a randomized controlled trial. Am J Kidney Dis. 2009;53(1):26-32

12. Pozzi C, Bolasco PG, Fogazzi GB, et al. Corticosteroids in IgA nephropathy: a randomised controlled trial. Lancet. 1999:353(9156):883-887.

13. Rauen T, Eitner F, Fitzner $C$, et al; STOP-IgAN Investigators. Intensive supportive care plus immunosuppression in IgA nephropathy. N Engl J Med. 2015;373(23):2225-2236

14. Levey AS, Stevens LA, Schmid CH, et al CKD-EPI (Chronic Kidney Disease Epidemiology Collaboration). A new equation to estimate glomerular filtration rate. Ann Intern Med. 2009; 150(9):604-612
15. Cattran DC, Coppo R, Cook HT, et al; Working Group of the International IgA Nephropathy Network and the Renal Pathology Society. The Oxford classification of IgA nephropathy: rationale, clinicopathological correlations, and classification. Kidney Int. 2009;76(5):534-545.

16. Coresh J, Turin TC, Matsushita K, et al; CKD Prognosis Consortium. Decline in estimated glomerular filtration rate and subsequent risk of end-stage renal disease and mortality. JAMA. 2014; 311(24):2518-2531

17. Levey AS, Inker LA, Matsushita K, et al. GFR decline as an end point for clinical trials in CKD: a scientific workshop sponsored by the National Kidney Foundation and the US Food and Drug Administration. Am J Kidney Dis. 2014;64(6):821-835.

18. Li X, Liu Y, Lv J, et al. Progression of IgA nephropathy under current therapy regimen in a Chinese population. Clin J Am Soc Nephrol. 2014;9 (3):484-489

19. Inker LA, Mondal H, Greene T, et al. Early change in urine protein as a surrogate end point in studies of IgA nephropathy: an individual-patient meta-analysis. Am J Kidney Dis. 2016;68(3):392-401.

20. Barbour SJ, Cattran DC, Kim SJ, et al. Individuals of Pacific Asian origin with IgA nephropathy have an increased risk of progression to end-stage renal disease. Kidney Int. 2013;84(5): 1017-1024.

21. Tesar V, Troyanov S, Bellur S, et al.

Corticosteroids in IgA nephropathy: a retrospective analysis from the VALIGA study. J Am Soc Nephrol. 2015;26(9):2248-2258.

22. Fellström BC, Barratt J, Cook H, et al; NEFIGAN Trial Investigators. Targeted-release budesonide versus placebo in patients with IgA nephropathy (NEFIGAN): a double-blind, randomised, placebo-controlled phase 2b trial. Lancet. 2017;389 (10084):2117-2127.

23. Connell JM, Whitworth JA, Davies DL, Lever AF, Richards AM, Fraser R. Effects of ACTH and cortisol administration on blood pressure, electrolyte metabolism, atrial natriuretic peptide and renal function in normal man. J Hypertens. 1987;5(4): 425-433.

24. Smets $P$, Meyer $E$, Maddens $B$, Daminet $S$. Cushing's syndrome, glucocorticoids and the kidney. Gen Comp Endocrinol. 2010;169(1):1-10. 